\title{
Experimental Study of Crack Growth Arrest Using Stop-Drilled Hole (SDH) with Pre-Stress
}

\author{
Yudi Dwianda, ${ }^{\mathrm{a},}$ and Tulus Swasono, ${ }^{\mathrm{a}}$ \\ a) Maintenance and Repair Engineering Department, Polytechnic of Kampar, Indonesia \\ *Corresponding author: dwianda@googlemail.com
}

\section{Paper History}

Received: 29-January-2020

Received in revised form: 04-February-2020

Accepted: 30-March-2020

\begin{abstract}
When critical cracks are detected, the choice of one or a combination of repair techniques to be used depends on many factors, such as crack conditions, expected precision, type of material, availability of tools and experience required. One method is to make Stop-Drilled Hole (SDH) at the ends of the crack. This research examines crack growth arrest in the form of Stop-Drilled Hole. Variation was given the initial stress (PreStress) with a combination of variations in the size of the SDH. This combination has a varied effect on the average critical load that can be held before cracking propagates. In this study, it was found that the greater the dimensions of the $\mathrm{SDH}$, the average critical load needed to re-propagate the crack also increases. It was also found that the initial stress applied to the SDH would raise the average value of the critical load.
\end{abstract}

KEY WORDS: Crack, Propagation, Stop-Drilled Hole, PreStress.

\section{NOMENCLATURE}

SDH Stop-Drilled Hole

\subsection{INTRODUCTION}

The development of engineering applications always faces material problems. With increasing metal working capabilities, the application of metal materials to structures increases rapidly. The use of metal in structures is not always satisfactory because unexpected failures often occur. Some of these failures are caused by poor design, but later it was discovered that material defects in the initial formation process can cause cracks and breaks. On other occasions failures often occur in low loading conditions, so that more extensive research is conducted. In that study it was found that high stress concentrations were the cause of failure [1].

In many cases of failure (fracture) is caused by fatigue (fatigue) where the crack growth period starting from the emergence of the crack until the failure lasts long enough. Then the crack can be easily suppressed through periodic inspections and the treatment can be carried out as follows:

(a) Dismantling the system and replacing cracked components or entire structures

(b) Reducing external loads and continuing with tight control of crack growth

(c) Arrest, stop or eliminate cracks.

Conventional repairs involving comprehensive replacements such as treatment (a) take a lot of time and large costs, while reducing workload on components that are mostly cracked cannot be done, then a fast and simple method of anchoring or arresting crack growth is the best solution [2]. Meanwhile there is no one best repair method that can be used in all cases. Although there are quite a lot of studies on the types of crack repair as reviewed by Mazarni et.al. [3]. Types of improvements include; Welding, metal stitching, gluing and patching. Each type of repair has its own conditions to be used. When critical cracks are detected in mechanical components or structures, several methods are used to hold or stop the growth or propagation of further cracks. The choice of one or a combination of repair techniques that will be used depends on many factors, such as crack conditions, crack position, crack orientation, crack size, component thickness, and expected precision, type of material, tool availability and required experience. To prevent the propagation of cracks in narrow workspace conditions Macabe and his colleagues in his research suggested the use of Stop-Drilled Hole (SDH) method [4]. 
There is quite a lot of research on crack growth arresting uses these SDH. Macabe et.al. (2014) [4] for example conducted research on the use of pins in inhibitory holes. Numerical research on the use of inhibitory holes $(\mathrm{SDH})$ to resist the propagation of cracks has also been carried out by Dwianda et.al. [5]. Crack growth arrested studies using stiffeners have also been carried out [6].

\subsection{METHODOLOGY}

The research method of crack growth arrest using SDH with prestress follows a process such as a research flowchart which is explained as follows:

\subsection{Literature Review}

The research begins by collecting and studying the literature relating to the title of the research to look for research that have been done before, theories that support this research and those related to methods to arrest the crack growth, especially about arresting crack growth in the form of holes.

\subsection{Design of Test Specimens}

After getting enough literature, the research process was continued to the specimen design stage. Discussions with all team members are needed to examine all aspects such as test specimen standards, equipment constraints, obstacles that may occur during the manufacturing process, treatment of specimens and so on.

Test specimen material is low carbon steel plate with $10 \mathrm{~mm}$ thickness. This plate is formed into a specimen with a size of 50 X $200 \mathrm{~mm}$. Dimension of specimen are taken with reference to the literature studies that have been carried out. The specimen is given an initial crack (gap) with a length of $25 \mathrm{~mm}$ or half the width of the plate. Specimens without SDH were made as comparative specimens.

In the design of this test specimen, the inhibitory hole is varied in dimensions. These variations are holes with diameters of $4 \mathrm{~mm}, 6 \mathrm{~mm}$ and $8 \mathrm{~mm}$. In addition to dimensions, SDH are also varied by providing pre-stress for a portion of the specimen for each variation of the SDH.

\subsection{Making Test Specimens}

The making of the test specimen was carried out in a workshop with supervision from the research team to obtain the test specimen in accordance with the design.

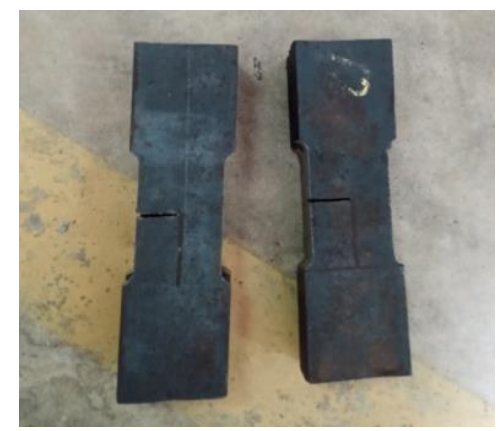

Figure 1: Specimens with a gap without holes.
There are three types of test specimens namely; specimens without hole $(\mathrm{SDH})$, specimens with SDH without initial stress and specimens with initial stress (pre-stress). Variations in the hole dimensions are also applied to these two types of specimens that have hole. So overall there are seven variations of the specimens that will be tested in this study.

Initial loading is carried out in such a way that the purpose of the pre-stress can be achieved. For that the initial loading will be controlled by automatic machines.

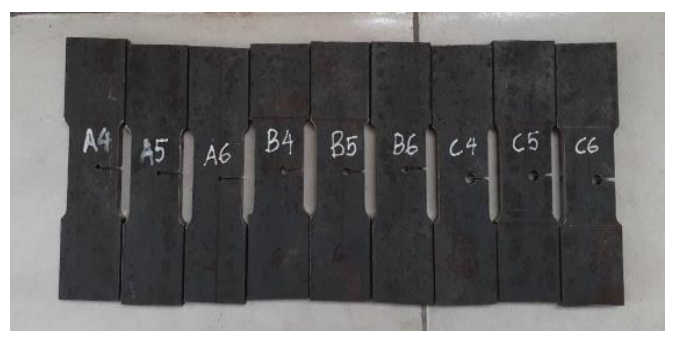

Figure 2: Specimens with SDH $4 \mathrm{~mm}, 6 \mathrm{~mm}$ and $8 \mathrm{~mm}$.

\subsection{Experiment}

The test is carried out using a Computerized Servo Control Material Testing Machine. The application software used by this machine is the U.T.M program UTM0906. Before testing is done each specimen is coded according to the variations.

- Code "T" is used for specimens without holes.

- Code "AT" for specimens with $4 \mathrm{~mm} \mathrm{SDH}$ without pre-stress.

- Code "ADP" for specimens with a $4 \mathrm{~mm} \mathrm{SDH}$ with pre-stress.

- Code "BT" for specimens with $6 \mathrm{~mm} \mathrm{SDH}$ without pre-stress.

- Code "BDP" for specimens with $6 \mathrm{~mm}$ SDH with pre-stress.

- Code "CT" for specimens with $8 \mathrm{~mm}$ SDH without pre-stress.

- Code "CDP" for specimens with $8 \mathrm{~mm}$ SDH with pre-stress.

\subsection{RESULTS AND DISCUSSION}

This research studies the effect of variations in the size of the stop-drilled hole (SDH) in arresting crack growth. In addition, this study also studies the effect of giving initial stress (pre-stress) to crack growth arrest.

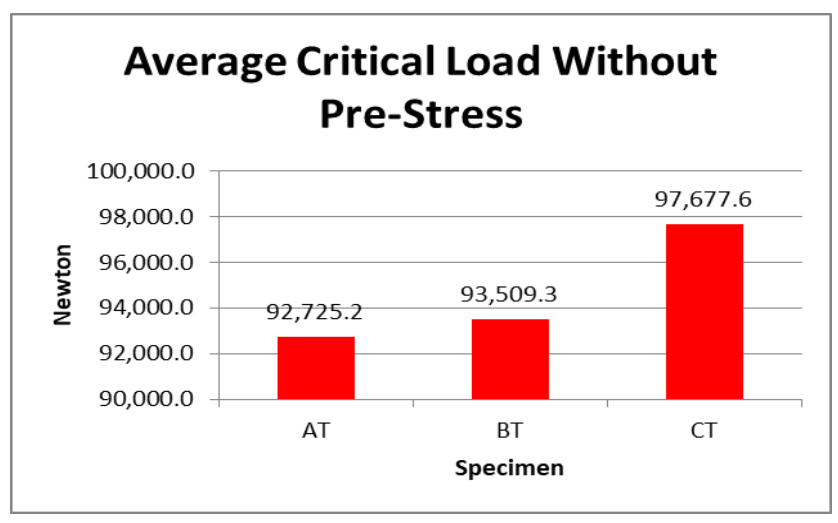

Figure 3: Chart of critical Load in specimens without pre-stress.

The effect of these two variables is seen by comparing the average 
value of critical loads for each variable. The effect of variation of SDH size on crack growth can be seen in Figure 3.

From the graph in Figure 3, it can be seen that the critical load obtained from specimen $\mathrm{C}(8 \mathrm{~mm})$ is greater than the critical load obtained from specimen B $(6 \mathrm{~mm})$. Tthe critical load obtained from specimen B $(6 \mathrm{~mm})$ is greater than the critical load obtained from specimen A $(4 \mathrm{~mm})$. The effect of variations in SDH size on crack growth in specimens that were given an initial stress (pre-stress) can be seen in Figure 4.

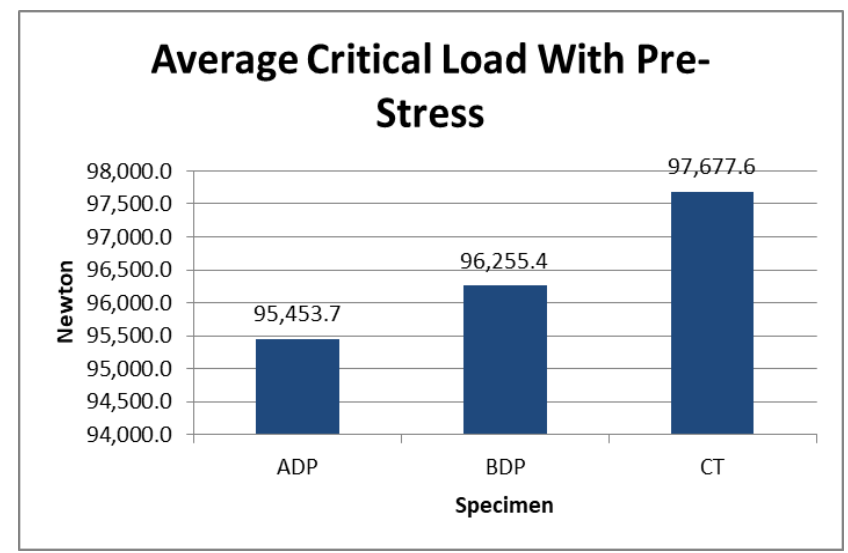

Figure 4: Chart of critical Load in specimens with pre-stress.

From the graph in Figure 4, it can be seen that the critical load obtained from specimen $\mathrm{C}$ that is greater than the critical load obtained from specimen B. While the critical load obtained from specimen B is greater than the critical load obtained from specimen $\mathrm{A}$. These results are relatively the same as the results obtained from the specimen without pre-stress. To see the effect of pre-stress to SDH on crack growth compared to specimens with the same SDH size without initial stress and with initial stress. The results can be seen in Figure 5.

From the graph in Figure 5, it can be seen that the average critical load value of the AT specimen is lower than the ADP. The average value of BT's critical load is lower than BDP and the average value of CT's critical load is lower than CDP. So at the same hole size the critical load value of the specimen without initial stress is lower than the specimen given initial stress.

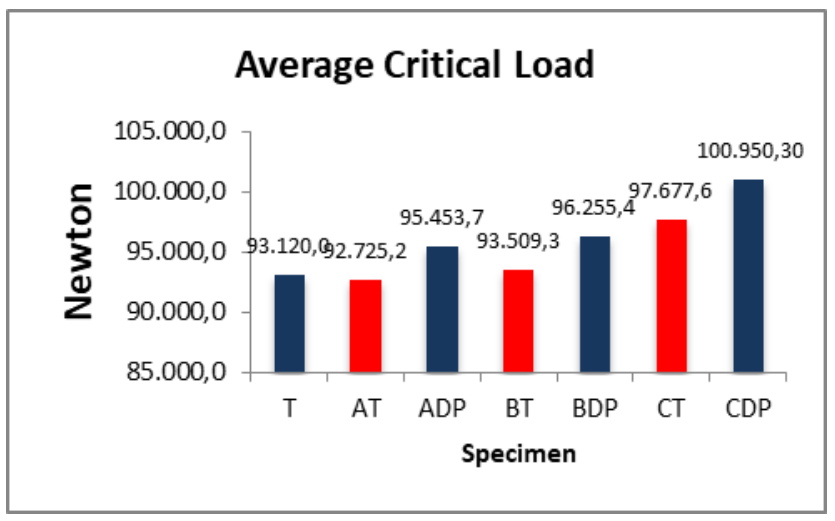

Figure 5: Graph of comparison of critical loads of all specimens.

\subsection{CONCLUSION}

From the research that has been done it can be concluded that:

1. The Stop drilled hole (SDH) affects the rate of crack propagation in increasing the critical load value before the crack propagates.

2. The diameter of the SDH also affects the growth of cracks where the greater the dimensions of SDH then the average value of the critical load required for cracks begins to spread even greater.

3. Giving initial stress (pre-stress) to the specimen can increase the value of the critical load compared to specimens that are not pre-stressed.

\section{ACKNOWLEDGEMENT}

A big thanks you to the Directorate General of Higher Education and LDikti X, who have been willing to fund this research using the PDP scheme.

\section{REFERENCE}

1. Broek D. 1982. Elemetary Engineering Faracture mechanics 3th ed. Martinus Nijhoff Publishers. The Hague.

2. Domazet Z. 1996. Comparison of Fatigue Crack Retarding Methods. Engineering Failure Analysis, Vol. 3, No. 2, pp 137 - 147.

3. Marazani T., Madyira D. M., Akinlabi E. T. 2017. Repair of cracks in metals: A review. 14th Global Conference on Sustainable Manufacturing, GCSM 3-5 October 2016, Stellenbosch, South Africa Procedia Manufacturing 8 (2017) 673-679.

4. Macabe C., Naka K., Ferdous M. S. 2014. Method of Arresting Crack Growth for Application at Narrow Working Space. Bulletin of the JSME, Mechanical Engineering Journal Vol.1, No.6.

5. Dwianda Y., Dahlan H., Rusli M. 2017. Kaji Numerik Pencegahan Pertumbuhan Retak dengan Menggunakan Metode Modifikasi Bentuk Stop Drilled Hole (SDH). Media Mesin: Jurnal Ilmiah Teknik Mesin Vol. 18, No. 2, 76-82.

6. Dahlan H., Dwianda Y., Rusli M. 2018. Kaji Eksperimantal Pencegahan Pertumbuhan Retak dengan Menggunakan Pengaku. Media Mesin: Jurnal Ilmiah Teknik Mesin Vol. 19 No. 2, 74-83. 